\title{
Reliability Analysis of an Underground Reinforced Concrete Rectangular Water Tank
}

\author{
Sani, J. E. ${ }^{1}$ Nwadiogbu, C. P. ${ }^{2^{*}}$ and Yisa G. L. ${ }^{1}$ \\ ${ }^{1}$ Department of Civil Engineering, Ahmadu Bello University, Zaria \\ ${ }^{2}$ Department of Civil Engineering, Federal Polytechnic Kaura Namoda, Zamfara.
}

\begin{abstract}
The failure of reinforced concrete rectangular underground water tank designed according to ${ }^{l}$ has been analyzed using the First Order Reliability Method. In doing this, the limit state functions were defined for both the ultimate state conditions (flexure, shear and torsion) and serviceability limit state (cracking) for both the tank wall and floor slab. Some basic variables present in the limit state function are used to study their variation with the reliability index and hence their significance in order to ensure safe design.

The results obtained revealed that the design requirement for floor slab in tension yields the lowest performance level and as such the requirement becomes the principal factor to be considered when alternative technique suggested by ${ }^{2}$ is not employed in the design of the wall and floor slab. It was also shown that increase in the span of the slab leads to the decrease in the performance of the tank or leads to the decrease in the reliability index making the tank on safe. It may be suggested that for the purpose of suitability and economy, the span should be between $5000 \mathrm{~mm}$ to $7000 \mathrm{~mm}$. The result also shows that as reinforcement ratio increases safety index increases and a reinforcement ratio of 0.01 to 0.02 is recommended for economic design.

Key words: First Order Reliability Method, failure due to Flexure, Failure due to shear, Failure due to torsion, Failure due to crack, Safety index, ${ }^{\text {. }}$
\end{abstract}

\section{Introduction}

The retention of liquid within water retaining structures (i.e. tank) is obviously of importance and detailed construction must be given to the control of cracking both as result of loading and due to temperature and shrinkage effect. Detailed design must therefore address not only ultimate strength considerations but, equally importantly, serviceability conditions.

All structures have two basic requirements in common; safety from collapse and satisfactory performance of the structure for its intended use. The limit states define the various ways in which a structure fails to satisfy these basic requirements. Ultimate limit states relate to satisfactory performance and correspond to excessive deflection, vibration and local deformation. Limit state design thus refers to the calculations made by the designer to ensure that these failures do not occur. A means of determining the consistency and efficiency of these limit states and the probability that these limit state is being attained or exceeded is by reliability evaluation of these "limit state" ${ }^{3}$.

Almost all of integrated structures are required to perform their expected functions with high level of reliability during the prescribed service time. Particularly, in case where failure or fracture of such structures might cause fatal loss of lives, structural reliability assurance is indispensable from a viewpoint of safety. In addition, this reliability assurance becomes of crucial importance also from an economical point of view such as savings of energy as well as natural resources, device in expenses and degradation of societal capital to be assured by protecting them against failure or fracture ${ }^{4}$.

In general, most of practical structures are usually subjected to randomly varying external loads, and the strengths of their identical components will never be the same even under the same loading conditions. In other words, both the loading and the strength are in deterministic in nature. In addition, a variety of uncertainty factors will inevitably arise in the processes of their construction and maintenance. Hence, in order to perform their rational design and maintenance, these uncertainties have to be properly evaluated on a probability basis. This is why reliability should be emphasized and the reliability-base design methodology plays a role of vital importance in the rational design.

Reliability is commonly defined as "the probability of a structure performing its purpose adequately for the period of time intended under the operating conditions encountered". There are four elements to the definition that must be considered. First, probability refers to the likelihood that a structural component will work properly. These terms imply acceptance of some degree of uncertainty. The second element refers to adequate performance. In order to determine whether a component has performed adequately, a standard is needed to define what is meant by adequate performance. The third element is the intended period of time. This is the mission endurance or lifetime of the structure under consideration. The final element of the definition is the operating conditions; environmental conditions play a large role in reliability of structures ${ }^{5}$ and 6 . 
Structural reliability theory is concerned with the rational treatment o uncertainties in structural engineering and with the method of assessing the safety and the serviceability of civil engineering and other structures. Reliability is therefore the branch of structural engineering which is concerned with the analysis and probabilistic assessment of design random variable in order to predict whether specified limit state would be violated and in doing this, uncertainties existing in structural engineering fields are taken into consideration.

Thus, there is a need for all structural engineers to develop an understanding of structural reliability theory and for it to be applied in the designs and constructions encountered either through codes or by direct application in the case of special structures. The aim in the above cases is to achieve economy together with an appropriate degree of safety.

\section{Water Retaining Structures}

In design of liquid retaining structures, certain requirements have to be fulfilled in addition to having adequate strength, durability and freedom from excessive cracking and deflection; it must be designed such that water does not leak or percolate through the structures.

Historically, design has been based on elastic theory, with specified maximum design stresses in the material under service conditions. Limit state philosophy has recently been introduced providing a more logical base for determining safety factor. The limit state design method enables the different failure modes of structures to be identified so that premature form of failure may be prevented. In addition, it is ensured that failure for water structures have low permeability so as to prevent leakage through the concrete and also provide adequate durability and prevention against corrosion of the reinforcement.

In this particular design, the base of the tank rest directly on the ground and the bearing capacity of the soil beneath the tank is adequate to sustain the weight of the tank. It is also assumed that the tank floor slab is monolithically connected to the wall of the tank.

\section{Forces on the Rectangular Tank}

The principal forces on the wall and bottoms of tanks are fluid pressure and soil pressure on the lower face on the bottom of the tank. A rectangular tank, the walls resists the horizontal pressure by ring tension.

\section{Analysis of Rectangular Tank}

The stresses acting and the plane faces of the element are resolved in the direction of the coordinate axis, and the stress components are denoted by

$N_{y} \& N_{x}$ - forces per unit length in their respective planes.

$N_{x y} \& N_{y x}$ - shear forces per unit length

$\mathrm{X}, \mathrm{Y} \& \mathrm{Z}$ - Applied external forces per unit area

$\mathrm{dx} \& \mathrm{dy}$ - elemental length.

Stress resultant are forces (moments) per unit length of the sides of the tank as shown in fig. 1

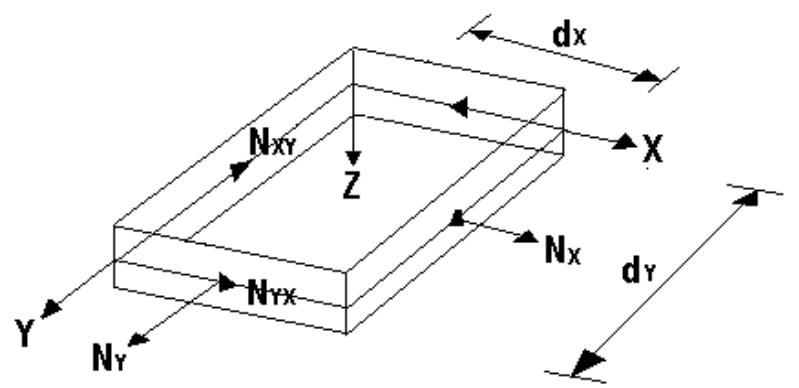

Fig 1 Membrane Stress Resultants

\section{Bending Stresses Resultants}

From Fig. 1, we have the following forces and moments:

$M_{x}=$ normal bending moment acting upon X-plane

$M_{y}=$ normal bending moment acting upon Y-plane

$M_{x y}=$ torsional moments acting upon X-plane

$M_{y x}=$ torsional moment acting upon Y-plane

$Q_{x}=$ transverse shear force per unit length acting on X-plane

$Q_{y}=$ transverse shear force per unit length acting on Y-plane

The value of moments and shear force in figure 2 are derived in terms of bending theory. 


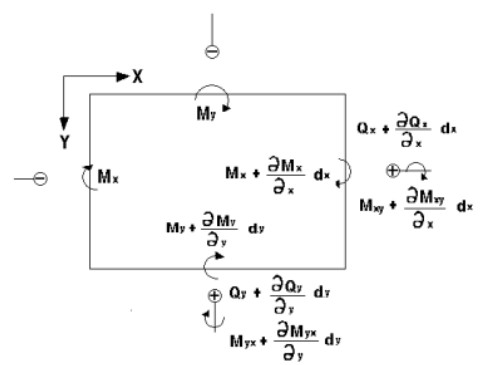

Resolving forces vertically.

Fig. 2 Bending Stress Resultant

$\frac{d Q_{x} d x d y}{d x}+\frac{d Q_{y} d x d y}{d y}+W d x d y=0$

Taking moments about $\mathrm{x}$-axis and ignoring second order terms

$$
\frac{d M_{x} d x d y}{d x}+\frac{d M_{y} d x d y}{d y}-Q_{x} d x d y=0
$$

Taking moments about y-axis and ignoring second order terms

$$
\begin{gathered}
-\frac{d M_{y} d y d x}{d y}+\frac{d M_{x y} d x d y}{d x}-Q_{y} d x d y=0 \\
\frac{d Q_{x}}{d x}+\frac{d Q_{y}}{d y}=-W \\
\frac{d M_{x}}{d x}+\frac{d M_{y x}}{d y}=Q_{x} \\
\frac{d M_{y}}{d y}-\frac{d M_{x y}}{d x}=Q_{y}
\end{gathered}
$$

Hence;

From theory of plate, it is shown that;

$M_{x y}=-M_{y x}$

Differentiating equations ( $5 \& 6$ ) with respect to $\mathrm{x}$ and y respectively and substituting in equation (4), the basic equilibrium equation for a thin plate or slab is obtained as follows;

$$
\frac{d^{2} M_{x}}{d x^{2}}+\frac{d^{2} M_{y}}{d y^{2}}-\frac{2 d^{2} M_{x y}}{d x d y}=-W
$$

\section{Rectangular Slab Simply Supported on Four Sides}

The Grashof - Rankine method assumes that a uniformly distributed load on a rectangular slab is shared between strips running in two directions parallel to the sides of the slab,. Assuming all torsional moments are neglected as well as any interaction between the X-strips and the Y- strips, the strips can be designed as beam.

Then from equation (8)

$$
\begin{gathered}
\frac{d^{2} M_{s x}}{d x^{2}}=-n_{x} \\
\frac{d^{2} M_{s y}}{d y^{2}}=-n_{y}
\end{gathered}
$$

Where,

$n_{x}+n_{y}=n=W$

and;

$\mathrm{n}=$ total design load per unit area of collapse. $=1.4 G_{k}+1.6 Q_{k}$ 
The ratio of $n_{x}$ and $n_{y}$ is determined by compatibility requirements such that the mid-span deflections of the central strips in the two directions are equal.

\section{Rectangular Slab Restrained on Four Sides}

In yield line theory, there are two well known methods of analysis. They are

i. $\quad$ Virtual work method

ii. Johansen's equilibrium method

Both methods are based on a postulated yield-line pattern. In the virtual work method, the internal work done on the slab (which is the sum of the rotations in the yield lines multiplied by the ultimate resistance moments) is equated to the external work done by the loads (which is the sum of the loads multiplied by their respective deflection), while in the equilibrium method, the equilibrium equations are obtained for each element by taking moments and resolving vertically, The equations are then solved simultaneously to obtain the solution.

Using Hellerbong strip method, the value of $M_{x}$ and $M_{y}$ at any point of a rectangular slab is

$$
\begin{gathered}
M_{x}=\frac{1}{2} n_{x}^{2} \\
M_{y}=\frac{1}{2} n_{y}^{2}
\end{gathered}
$$

The maximum value of Mx and My at the centre of the slab is

$$
\begin{aligned}
& M_{x}=\frac{1}{2} n(\alpha l)^{2} \\
& M_{y}=\frac{1}{2} n\left(\frac{1}{2} \lambda l\right)^{2}
\end{aligned}
$$

Fig. 3

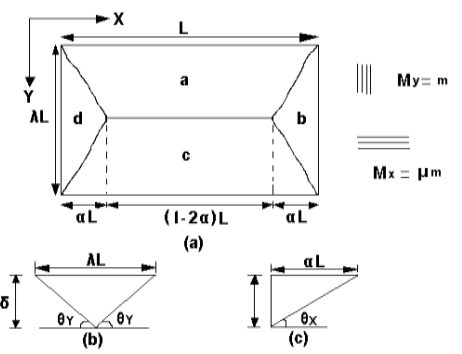

The slab (figure $3 \& 4$ ) is given by the four diagonals $\mathrm{AE}, \mathrm{EF}, \mathrm{CF}$ and $\mathrm{DE}$, which equals four times the resistance moment of any single diagonal.

Hence X diagonal

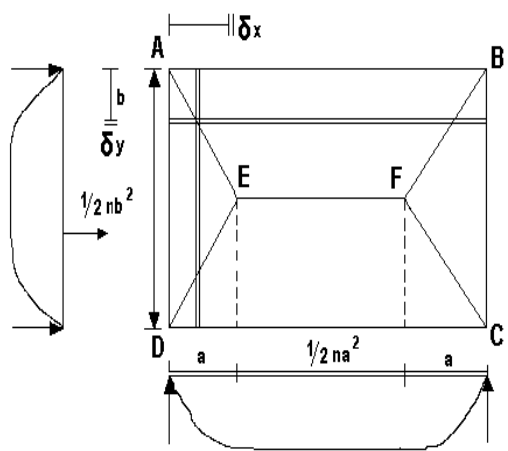

Fig. 4

$$
\sum M_{x} \delta y=4 \int_{0}^{\frac{1}{2} \lambda l} M_{x} d y=2 n \int_{0}^{\frac{1}{2} \lambda l} x^{2} d y
$$

Where $M_{x}=\frac{1}{2} n_{x}^{2} \quad$ along yield line AE 
But by ratio

$$
\frac{x}{y}=\frac{\alpha l}{\frac{1}{2} \lambda l} \therefore x=\frac{2 \alpha}{\lambda} y
$$

Therefore $\sum M_{x} \delta y=2 n\left(\frac{2 \alpha}{\lambda}\right)^{2} \int_{0}^{\frac{1}{2} \lambda l} y^{2} d y$

$$
\begin{aligned}
& \qquad=8 n\left(\frac{\alpha}{\lambda}\right)^{2} \times \frac{1}{3}\left(\frac{\lambda l}{2}\right)^{3} \\
& =\frac{1}{3} n(\alpha l)^{2} \lambda l \\
& M_{x}=\frac{1}{2} n(\alpha l)^{2} \text { which is the maximum value then }
\end{aligned}
$$

$$
\sum M_{x} d x=\frac{1}{3}(2 \lambda l) M_{x}
$$

Similarly, $\sum M_{y} \delta x$ for diagonals only equals

$$
\frac{1}{3}(4 \alpha l) M_{y}
$$

Where $M_{y}=$ maximum value of $M_{y}=n\left(\frac{1}{2} \lambda l\right)^{2}$

$\sum M_{y} \delta x$ for yield line EF is simply $(1-2 \alpha) l M_{y}$

Using virtual work Method,

$$
\begin{aligned}
& \sum W \delta=\sum M \theta \\
& n \lambda l^{2}\left(\frac{1-2 \alpha}{2}+\frac{2 \alpha}{3}\right) \delta=2(1-2 \alpha) M_{y}(2 \delta)+\frac{1}{3}(2 \lambda) M_{x}\left(\frac{5 \delta}{\alpha}\right)+ \\
& \frac{1}{3}(4 \alpha) M_{y}\left(\frac{2 \delta}{\lambda}\right) \\
& \text { When } \alpha=\frac{\frac{\lambda}{2}}{\text { then }} M_{x}=M_{y} \\
& \quad M=\frac{n(\lambda l)^{2}}{8}=\frac{q l^{2}}{8}
\end{aligned}
$$

\section{Derivation of code equations for rectangular section}
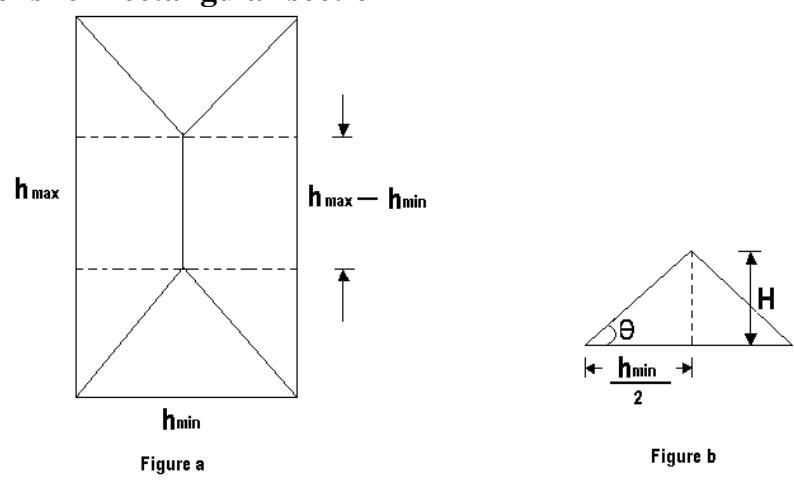

Fig. 5 


$$
\begin{aligned}
& \qquad \text { Volume }=\frac{1}{3} h_{\min }^{2} H+\frac{1}{2} h_{\text {min }}\left(h_{\max }-h_{\min }\right) H \\
& \quad \frac{h_{\min } H}{2}\left(h_{\max }-\frac{h_{\min }}{3}\right) \\
& =\text { But from figure (b) }
\end{aligned}
$$

Slope

$$
\begin{aligned}
& \begin{array}{l}
\theta=\frac{H}{h_{\min } / 2}=V_{t} \\
\quad=\frac{V_{t} h_{\min }}{2} \\
\text { ie } \mathrm{H} \quad=\frac{V_{t} h_{\min }^{2}}{4}\left(h_{\max }-\frac{h_{\min }}{3}\right) \\
\text { so volume } \\
\text { also } \mathrm{T}=\text { twice volume }
\end{array}
\end{aligned}
$$

$$
=h_{\min } H\left(\frac{h_{\min }}{3}+\frac{h_{\max }-h_{\min }}{2}\right)
$$

$$
\text { so } V_{t}=\frac{2 T}{h_{\min }^{2}\left(h_{\max }-\frac{h_{\min }}{3}\right)}
$$

\section{Reliability Analysis}

Reliability-based design is founded on the concept that one can estimate the probability of an undesirable event such as a fracture, occurring over the life time of a structure, despite the uncertainties involved. It is a design method that provides an assumed level of safety by reducing the probability of such an occurrence below the target value.

The fundamental concept of reliability analysis is that resistance and load factors are statistical quantities with a central tendency (mean), dispersion about the mean (variance) and some form of distribution (probability density function e.g. normal, lognormal, gumbel). When combined together via an expression to describe the limit state (such as failure or collapse). These will be a finite Probability of failure $\left(P_{f}\right)$ and since reliability is equals to $1-P_{f}$ the inherent reliability of the component against a particular failure mode and with given resistance properties is defined.

In reliability assessments, it is necessary to determine the probability that the structure will not attain any of the limit states likely to the violated within a reference period, in presence of uncertainties such as conditions of services, human errors, change in load and material properties e.t.c. The probability of a survival of a structure can be mathematically represented thus,

$$
R=1-P_{f}
$$

where $\mathrm{R}$ is survival probability and $P_{f}=$ probability of failure

This shows that the probability of survival of a structure is the compliment of the probability that the structure will fail.

\section{Resistant and Load Interaction}

In basic reliability problems, consideration is given to the effect of a load $\mathrm{S}$ and the resistance $\mathrm{R}$ offered by the structure. Both the load and resistant $\mathrm{S}$ and $\mathrm{R}$ can be described by a known probability density function $\mathrm{F}_{\mathrm{s}}$ ( ) and $\mathrm{F}_{\mathrm{r}}($ ) respectively. $\mathrm{S}$ can be obtained from the applied load through a structural analysis making sure that $\mathrm{R}$ and $\mathrm{S}$ are expressed in the same unit.

Considering only safety of a structural element, it would be said that a structural element has failed if its resistance R, is less than stress resultant S acting on it. The probability of failure Pf of the structural element can be expressed in any of the following ways

$$
P_{f}=P(R-S)
$$

Where $\mathrm{R}=$ strength (resistant) and $\mathrm{S}=$ loading in the structure. The failure in this case is defined in this region where $\mathrm{R}-\mathrm{S}$ is less than zero or $\mathrm{R}$ is less than $\mathrm{S}$ i.e. 


$$
P_{f}=P((R-S) \leq 0)
$$

As an alternative approach to equation 3.2, the performance function can also be given as

$$
P_{f}=P\left(\frac{R}{S} \leq 1\right)
$$

Where in this case, the failure is defined in the region where $\mathrm{P}_{\mathrm{f}}$ is less than one, or $\mathrm{R}$ is less than $\mathrm{S}$, that is

$$
P_{f} \leq 1 \text { or } \mathrm{R}<\mathrm{S}
$$

It could also be expressed as

$$
P_{f}=\mathrm{P}(\ln \mathrm{R}-\ln \mathrm{S} \leq 1)
$$

Or in general,

$$
P_{f=\mathrm{P}[\mathrm{G}(\mathrm{R}, \mathrm{S}) \leq 0]}
$$

Where $\mathrm{G}(\mathrm{x})$ is the "limit state function" and the probability of failure is an identical with probability of the limit state violation.

For any random variable $\mathrm{X}$, the cumulative distribution function $\mathrm{F}_{\mathrm{X}}(\mathrm{x})$ is given by

$$
F_{X}(x)=P(X \leq x)=\int_{-\infty}^{x} f x(y) d y
$$

Provided that $\mathrm{x} \geq \mathrm{y}$

It follows for the common, but special case where $\mathrm{R}$ and $\mathrm{S}$ are independent, the expression for the probability of

failure is

$$
P_{f}=P(R-S \leq 0)=\int_{-\infty}^{\infty} F_{R}(x) f_{s}(x) d x
$$

(34)

Expression (34) as known as the "convolution integral" and $\mathrm{F}_{\mathrm{R}}(\mathrm{x})$ is the probability that $\mathrm{R} \leq \mathrm{x}$, or the probability that the actual Resistance $\mathrm{R}$ of the member is less than some value $\mathrm{x} . \mathrm{F}_{\mathrm{S}}(\mathrm{x})$ represents probability that the load effect $S$ acting in the member has a value below $x$ and $x+\Delta x$ in the limit as $\Delta x \rightarrow 0$.

Considering all possible value of $\mathrm{x}$, total failure probability is obtained as follows:

$$
P_{f}=\int_{-\infty}^{\infty}\left[1-F_{s}(x)\right] F_{R}(x) d x
$$

i.e. sum of all the cases of resistance for which the load exceeds the resistance

\section{Derivation of Limit State}

Failure of Cover Slab

Mode I: Failure due to flexure:

For the structure to be safe against flexural failure, the limit state function is thus,

$$
\frac{0.87 f_{y} \rho^{\prime} b d\left(d-d^{\prime}\right)+0.156 f_{c u} b d^{2}}{1000}-\frac{Q_{k} l^{2}\left(1.4 a_{o}+1.6\right)}{8}
$$

Mode II: Failure due to torsion:

The torsion should satisfy the limit state function below,

$$
0.8 \sqrt{f_{c u}}-\frac{2 T}{h_{\min }^{2}\left(h_{\max }-h_{\min } / 3\right)}
$$

Mode III: Failure due to shear:

The shear force should satisfy the limit state function below;

$$
\frac{0.95 \times\left(\frac{f_{c u}}{25}\right)^{\frac{1}{3}} \times\left(\frac{100 A_{s}}{b d}\right)^{\frac{1}{3}} \times\left(\frac{400}{d}\right)^{\frac{1}{4}}}{\gamma_{m}}-\frac{Q_{k} l\left(1.4 a_{o}+1.6\right)}{2 b d}
$$

Failure Due to Floor Slab

Mode I: Failure due to flexure: 
$\frac{0.87 f_{y} \rho^{\prime} b d\left(d-d^{\prime}\right)+0.156 f_{c u} b d^{2}}{1000}-\frac{x}{2}\left[\left(d-\frac{x}{3}\right)+\rho^{\prime}\left(\alpha_{e}-1\right)\left(1-\frac{d^{\prime}}{x}\right)\left(d-d^{\prime}\right) d\right] \frac{N_{d} \beta_{1}^{\prime}}{d \beta_{2}}$

${ }_{\text {Where }} \beta_{1}^{\prime}=\frac{e-\bar{x}}{d}-1 \quad \beta_{2}=\frac{x}{2 d}\left(1-\frac{x}{3 d}\right)$

Mode II: Cracking:

I. Failure due to flexural tension in matured concrete

$$
0.2-\frac{9 a_{c r} \varepsilon_{m}}{2+5\left(\frac{a-c_{\text {min }}}{h-x}\right)}
$$

$$
\varepsilon_{2}=\frac{b_{t}(h-x)\left(a^{\prime}-x\right)}{3 E_{s} A_{s}(d-x)}
$$

II. Failure due to direct tension in immature concrete

$$
0.2-\frac{f_{c t}}{f_{b}} \frac{\phi}{2 \rho} T \frac{\alpha_{c}}{2}
$$

Failure of the Wall

$$
\text { Where } \rho=\frac{A_{s}}{A_{c}}
$$

The failure due to cracking (flexural tension in mature concrete) is given by;

$$
0.2-\frac{3 a_{c r} \varepsilon_{m}}{1+2\left(\frac{a-c_{\text {min }}}{h-x}\right)}
$$

$$
\varepsilon_{2}=\frac{b_{t}(h-x)\left(a^{\prime}-x\right)}{3 E_{s} A_{s}(d-x)}
$$

Examining failure of cover slab

\section{Result of reliability analysis}

Failure mode I, (failure due to flexure) is illustrated in fig. 1 to 3 . It was observed that the reliability index decreases as the load ratio and span increases, while the beta value do not vary much when plotted against reinforcement ratio where load ratio was kept constant. From this we can conclude that for a span above $1000 \mathrm{~mm}$ the tank is not safe.

Failure mode II, (failure due to torsion) is illustrated in fig. 4. It was observed that if the smaller dimension of the section is reduced failure increases, i.e. reliability level decreases. Also if the larger dimension is increase failure is also likely because reliability index decreases.

It was also observed that when reliability index is plotted against characteristic concrete strengths there was no much differences in the values of beta obtained which signified that it does not affect the safety of the tank no matter the value of characteristic value used.

Failure mode III, (failure due to shear) is illustrate in fig. 5. It was observed that as the load ratio increases from 1.5 to 3.5 the graph s becomes more and more complicated which implies that increase in the value of the load ratio can cause failure so it preferable to design within the load ratio of 1.5 to 2.5 .

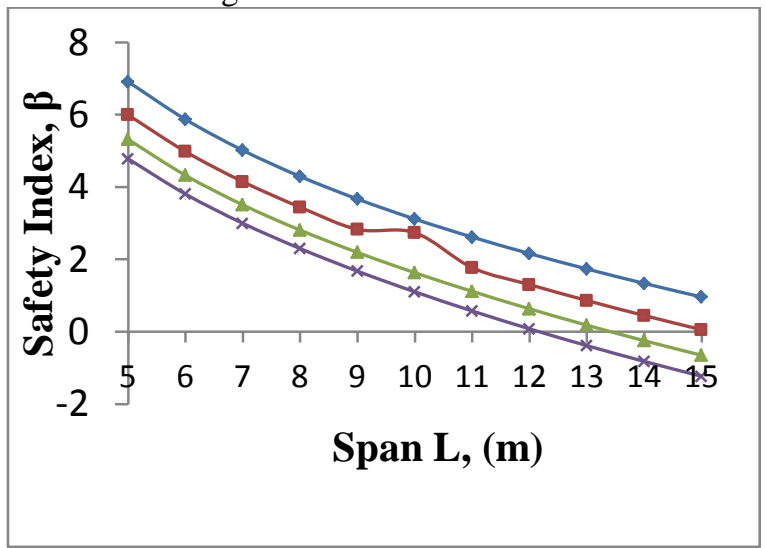




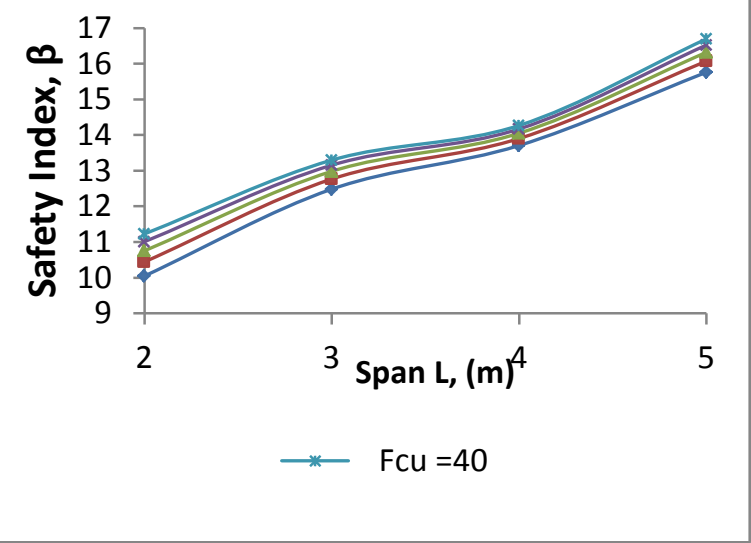

Fig. 4 Safety index against smaller dimension of section for cover slab in torsion

Fig. 1 Safety index against span for cover slab in flexure

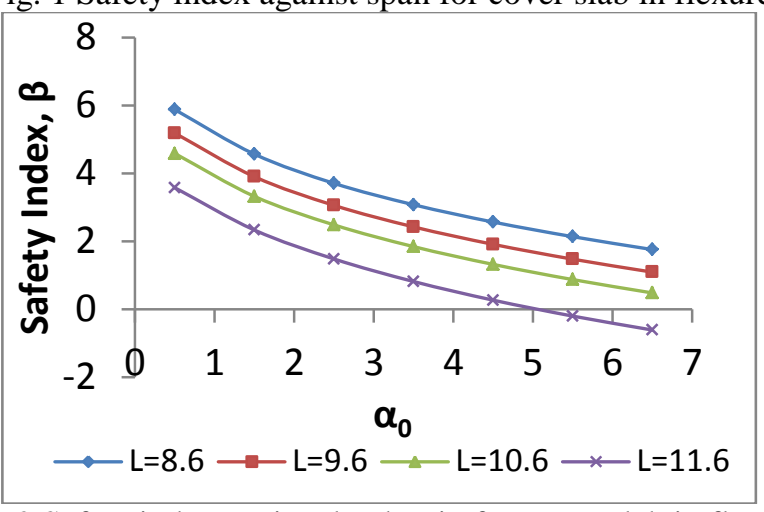

Fig. 2 Safety index against load ratio for cover slab in flexure

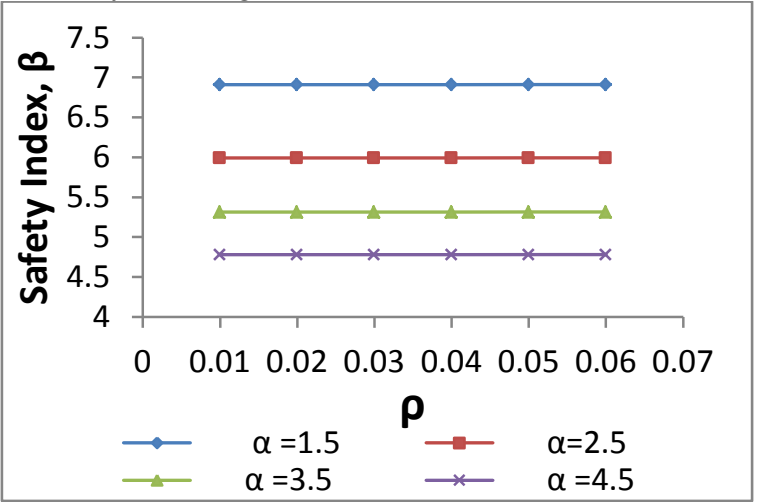

Fig. 3Safety index against reinforcement ratio for cover slab in flexure

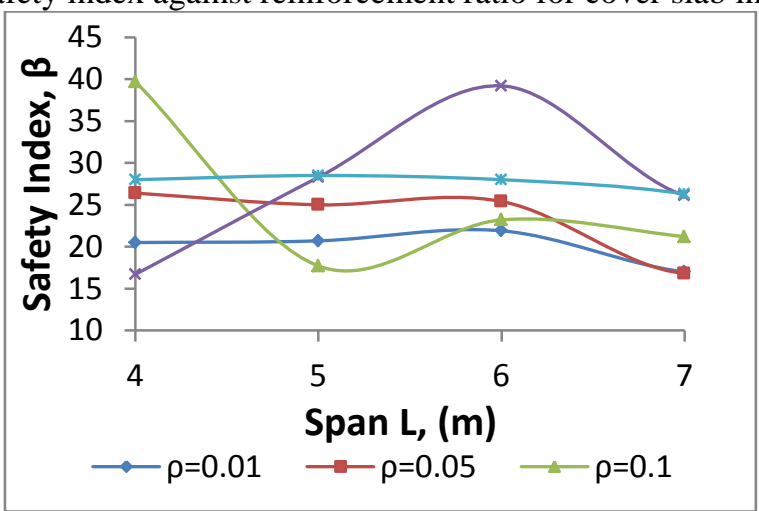

Fig. 5 Safety index against reinforcement ratio for cover slab in shear 


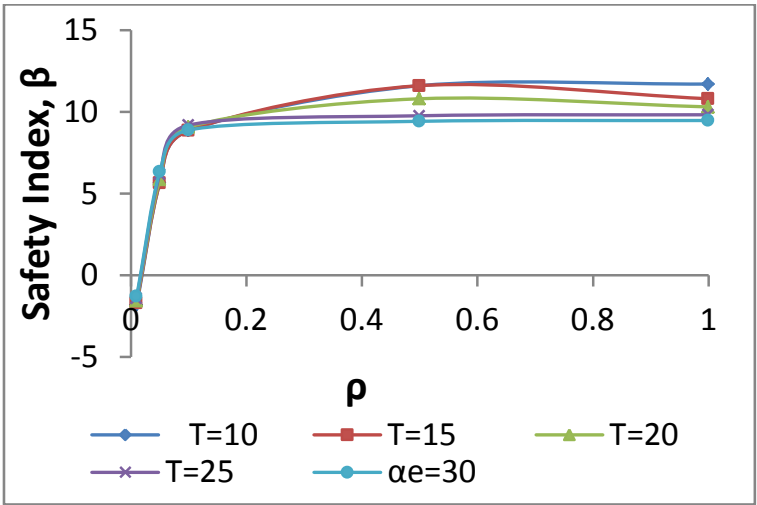

Fig. 6 Safety index against reinforcement ratio for floor slab in flexure when $b=800 \mathrm{~mm}$

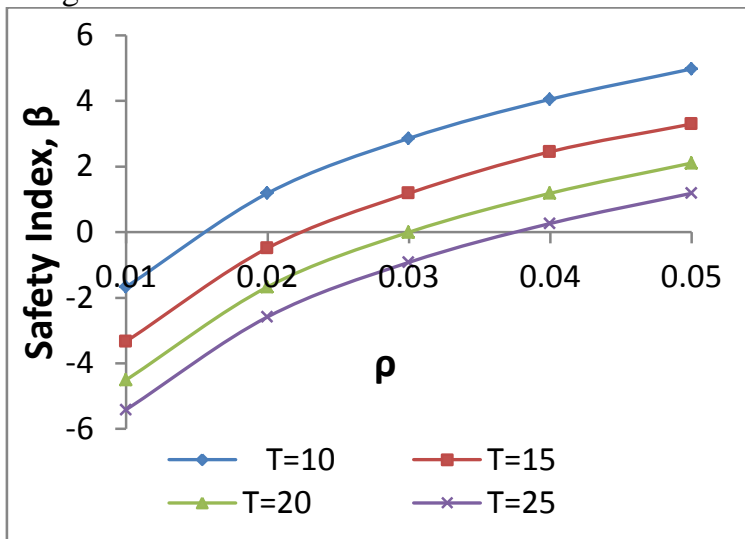

Fig. 7 Safety index against reinforcement ratio for floor slab in direct tension

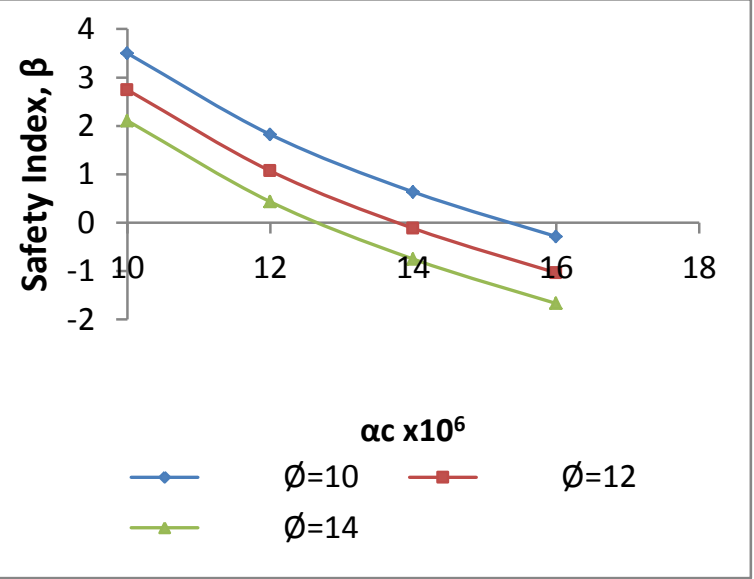

Fig. 8 Safety index against coefficient of thermal expansion for floor slab in direct tension

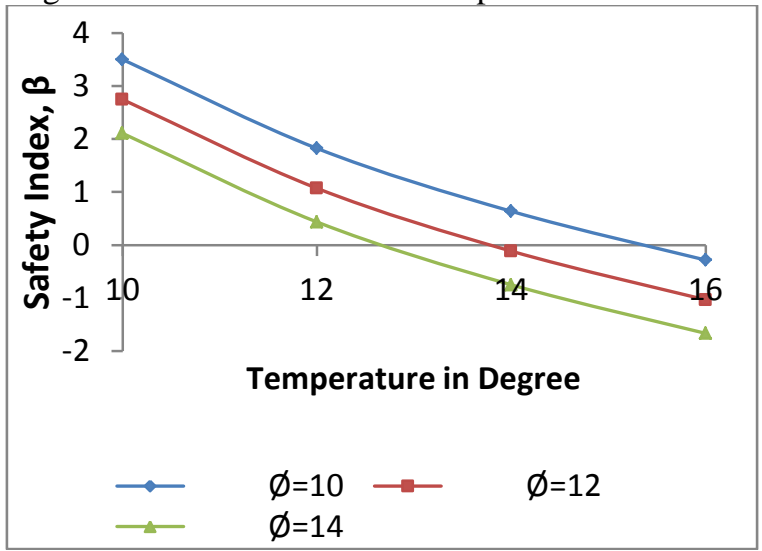

Fig. 9 Safety index against temperature for floor slab in direct tension 
Examining failure of floor slab

Failure mode I, (failure due to flexure) is illustrated in fig. 7 to 8 . It will be observed that as the reinforcement ratio increase the beta value increases and all the graph at increase in the width, has a minimum value of beta at a reinforcement ratio less than $1.5 \%$. So for sake of safety it is not advisable to use reinforcement ratio between $0.5 \%$ \& $1.0 \%$. For safe design a reinforcement ratio of $1.5 \%$ and above is preferable.

For a higher value of reinforcement ratio the design will no longer be economical since the aim of each design is to be economical as possible.

Failure mode III, (failure due to direct tension in immature concrete) is illustrated in fig. 9. It will be observed that as temperature increases the beta value reduces which implies that an increase in temperature leads to failure by cracking as expected for each structure. So therefore if the temperature rises above $15^{\circ}$ the tank will no longer be safe.

Also for increase in both coefficient of thermal expansion and bar diameter leads to a decrease in the value of beta will may result to failure.

\section{Conclusion}

The limit state functions for various failure modes for both the wall and the floor slab together with the cover slab of a rectangular underground water tank where suitably designed for probabilistic assessment. The level of failure, which is associated with each of the modes of failure, was computed using the First Order Reliability Method. It was observed that, as reinforcement ratio increases safety index increases.

It was noted that the serviceability failure modes yield safety indices than the modes of failure resulting from ultimate limit conditions, the condition for the flexure on the cover slab, (failure mode I) and the direct tension on the floor slab falls within the acceptable range of safety index. I.e. between 1 and 3

It was observed that for the failure modes, increase in span and temperature reduces the level of reliability of the tank. Hence, before making a choice of the dimension of the tank, it should be ensured that there would not be unnecessary waste of material, i.e., the section should be economical and safe The safety of reinforced concrete underground rectangular water tank is very much dependent on flexure and cracking conditions as revealed in this study. The use of post-tensioning should be employed instead of excessive thickness.

[1]. British Code of Practice. BS 8110: The Use of Concrete (1997)

[2]. Anchor, R. D. (1992). Design of Limit Retaining Concrete Structures (2 ${ }^{\text {nd }}$ edition). Publish by Hodda and Stoughton Press Ltd, St Edmundsbury

[3]. Allen, D. E. (1982). Canadian Buiding Digest CBD.221 Limit State Design. National Research Council Of Canada, Ottawa

[4]. Ishikawa, H. (1998). Important of Structural Safety and Reliability. http://www.eng.kagawa-u.ac.jp/

[5]. Doty, L. A. (1985). Reliability for the Technologies. Industrial Press New York.

[6]. Bazovsky, I. (1961). Reliability Theory and .Practice. Prentice-Hall, Inc, Englewood Cliffs, New Jersey. 